\title{
Modifier of Cell Adhesion Regulates N-Cadherin-Mediated Cell-Cell Adhesion and Neurite Outgrowth
}

\author{
Qi Chen, ${ }^{1}$ Tsan-Ju Chen, ${ }^{2}$ Paul C. Letourneau, ${ }^{2}$ Luciano Da F. Costa, ${ }^{3}$ and David Schubert ${ }^{1}$ \\ ${ }^{1}$ Cellular Neurobiology Laboratory, The Salk Institute for Biological Studies, La Jolla, California 92037, ${ }^{2}$ Department of Neuroscience, University of \\ Minnesota, Minneapolis, Minnesota 55455, and '3nstitute of Physics at São Carlos, São Carlos, São Paulo, Brazil
}

\begin{abstract}
Modifier of cell adhesion (MOCA) is a member of the dedicator of cytokinesis 180 family of proteins and is highly expressed in CNS neurons. MOCA is associated with Alzheimer's disease tangles and regulates the accumulation of amyloid precursor protein and $\beta$-amyloid. Here, we report that MOCA modulates cell-cell adhesion and morphology. MOCA increases the accumulation of adherens junction proteins, including N-cadherin and $\beta$-catenin, whereas reducing endogenous MOCA expression lowers cell-cell aggregation and $\mathrm{N}$-cadherin expression. MOCA colocalizes with $\mathrm{N}$-cadherin and actin in areas of cell-cell and cell substratum contact and is expressed in neuronal processes. MOCA accumulates during neuronal differentiation, and its expression enhances NGF-induced neurite outgrowth and morphological complexity. We conclude that MOCA regulates N-cadherin-mediated cell-cell adhesion and neurite outgrowth.
\end{abstract}

Key words: adhesion; cadherin; differentiation; MOCA; nerve; neurite outgrowth

\section{Introduction}

Cadherins are a superfamily of proteins that regulate many cellular functions, including cell adhesion and motility (Takeichi, 1991). Cadherins are also important for neuronal development and synapse formation, with a large number of the family members expressed in the brain (Takeichi, 1995). There are several subgroups within the cadherin superfamily, including classical cadherins, desmogleins, desmocollins, protocadherins, cadherinrelated neuronal receptors, Fats, seven-pass transmembrane cadherins, and the Ret tyrosine kinase (Yagi and Takeichi, 2000). Classical cadherins such as E-type and N-type are involved in forming both adherens and synaptic junctions in the nervous system. They make calcium-dependent homophilic bonds between their extracellular domains (Takeichi, 1995). The cytosolic domain of cadherins forms a complex with $\beta$-catenin and $\alpha$-catenin, which in turn associates with the actin cytoskeleton to modulate the cell adhesion and motility (Yap et al., 1997).

Modifier of cell adhesion [MOCA; also called presenilin (PS) binding protein and dedicator of cytokinesis 3 (DOCK3)] is a member of the DOCK180 family of proteins (Kashiwa et al., 2000; Brugnera et al., 2002; Cote and Vuori, 2002; Yajnik et al., 2003), and mutations in the gene are associated with an attention deficit hyperactivity disorder-like phenotype in humans (de Silva et al., 2003). MOCA was initially isolated by a yeast two-hybrid

Received June 18, 2004; revised Nov. 10, 2004; accepted Nov. 17, 2004.

This work was supported by grants from the National Institutes of Health (NIH) and the Alzheimer's Association of America to D.S. and by NIH Grant HD19950 to P.C.L. Q.C. was supported by the Bundy Foundation and by an NIH postdoctoral fellowship.

Correspondence should be addressed to Dr. David Schubert, The Salk Institute, 10010 North Torrey Pines Road, La Jolla, CA 92037. E-mail: schubert@salk.edu.

T.-J. Chen's present address: Department of Physiology, Kaohsiung Medical University, Kaohsiung, Taiwan, Republic of China.

DOI:10.1523/JNEUROSCI.3692-04.2005

Copyright $\odot 2005$ Society for Neuroscience $\quad$ 0270-6474/05/250281-10\$15.00/0 screen using the large hydrophilic loop of presenilin 1 as bait (Kashiwa et al., 2000). MOCA has 40\% homology to DOCK180, contains an Src homology 3 domain, and binds to Crk adapter proteins. Similar to DOCK180, MOCA activates Rac1 (Grimsley et al., 2004; Namekata et al., 2004) and alters the morphology of NIH3T3 cells (Namekata et al., 2004). Unlike most other PS interacting proteins, MOCA is only expressed in the brain. MOCA has been linked to Alzheimer's disease $(\mathrm{AD})$ pathology, because it is lost from the soluble fraction of $\mathrm{AD}$ brain relative to the agematched controls (Kashiwa et al., 2000) and accumulates in neurofibrillary tangles (Chen et al., 2001). In addition, MOCA decreases amyloid precursor protein (APP) and A $\beta$ secretion by regulating APP degradation, resulting in changes in APPdependent cell substratum adhesion (Chen et al., 2002). Therefore, MOCA may play a major role in CNS biology. Because a primary function of the DOCK 180 family of proteins is regulating cytoskeletal organization and cell-cell interactions, we studied MOCA in terms of cell adhesion. It is shown that MOCA is an active intermediate in the regulation of $\mathrm{N}$-cadherin-dependent adhesion and neurite outgrowth.

\section{Materials and Methods}

Accession numbers. The GenBank accession numbers for the nucleotide and protein sequence of MOCA reported in this study are AY145302, AY145303, and XM_236616.

Antibodies and chemicals. Monoclonal antibodies against adherens junction components, including $\mathrm{N}$-cadherin and $\beta$-catenin, were purchased from BD Biosciences (San Diego, CA) or from Santa Cruz Biotechnology (Santa Cruz, CA). An affinity-purified polyclonal antibody, which recognizes amino acid residues 2012-2027 of MOCA, was generated in rabbits (Kashiwa et al., 2000). Anti-hemagglutinin A antibodies MS-10P and SC-805 were purchased from Covance (Princeton, NJ) and Santa Cruz Biotechnology, respectively. Anti-actin antibody and the conjugated agarose beads were purchased from Sigma-Aldrich (St. Louis, MO).

Cells, transfection, and RNA interference. Four different cell lines were 
used in this study, including human embryonic kidney (HEK) 293T fibroblasts, the neuronal cell line B103 (Schubert et al., 1974), pheochromocytoma cell line (PC12), and a neuronal stem cell line HCN (Taupin et al., 2000). HCN cells were grown in defined medium as outlined in the original text. HEK293T and B103 cells were grown in DMEM supplemented with 10\% fetal bovine serum (FBS). Cell transfection was done using Lipofectamine 2000 reagent (Invitrogen, Carlsbad, CA). Stable transfection was done using either G418 or puromycin selection.

RNA duplexes were synthesized using a kit from Ambion (Austin, TX) according to the instructions of the manufacturer and their purity judged visually on polyacrylamide gels. Transfection was done using Oligofectamine reagent (Invitrogen). The targeting sequences for MOCA were: 5'GTAGTGGATTCAGACCAGA3' and 5'TAGAGGATTAGCAATTACA3'. A scramble sequence was used as a control: 5'CAGTCGCGTTTGCGACTGG3'. The short hairpin RNA (shRNA) constructs were generated using the plasmid vector, pSilencer2.1-U6 hygro from Ambion according to the instructions of the manufacturer and a green fluorescent protein (GFP) expression cassette was later incorporated into the constructs.

Western blotting and immunoprecipitation. Western blotting and secreted protein analysis were done as described previously (Chen et al., 2002). For immunoprecipitations (IPs), equal amounts of protein from cell lysates were immunoprecipitated with selected antibodies at $4^{\circ} \mathrm{C}$ overnight. Anti-mouse or anti-rabbit IgG agarose $(25 \mu \mathrm{l})$ (Roche Products, Indianapolis, IN) was then added to each sample and incubated at $4^{\circ} \mathrm{C}$ for $2 \mathrm{~h}$ on a rocker platform. The immunoprecipitates were collected by centrifugation and washed four times with the washing buffer $(0.1 \%$ Triton X-100, 20 mM HEPES, 150 $\mathrm{mm} \mathrm{NaCl}, 10 \%$ glycerol). The agarose beads were resuspended in $30 \mu$ of SDS-PAGE sample buffer and boiled for 3 min to release the proteins. After $1 \mathrm{~min}$ of centrifugation, the supernatants were separated on 10 or $12 \%$ Trisglycine gels. For pulse-chase experiments, cells were incubated in methionine-free DMEM for $90 \mathrm{~min}$ and labeled with $\left[{ }^{35} \mathrm{~S}\right]$-methionine $(400$ $\mu \mathrm{Ci} / \mathrm{ml}$ in methionine-free DMEM plus $5 \%$ dialyzed FBS) for $10 \mathrm{~min}$ at $37^{\circ} \mathrm{C}$, and the medium was replaced with "cold” DMEM medium plus 10\% FBS. Cells were lysed after different periods of time and subjected to IPs.

Northern hybridization and reverse transcription-PCR. Total RNA was isolated using Trizol reagents (Invitrogen), and mRNA was purified using an mRNA purification kit (Amersham Biosciences, Arlington Heights, IL). Two micrograms of mRNAs from each sample were used for Northern blotting analysis. An N-cadherin cDNA construct was obtained from Dr. Coleman (Mount Sinai School of Medicine, New York, NY) and used for making a probe. Reverse transcription (RT)-PCRs were performed as described previously (Chen et al., 2002). Two N-cadherin primer sets were used for PCRs: (1) 5'CACCCAACATGTTTACAATCAACAATGAGAC3' (forward) (nt1155-1185) and 5'-CTGCAGCAACAGTAAGGACAAACATCCTATT3' (reverse) (nt1598-1568); (2) 5'GGCTTAATGGTGATTTTGCTCAGCT3' (forward) (nt2172-2196) and 5'CTCAAGTCATAGTCCTGGTCTTCTTCTCCTCC3' (reverse) (nt2568-2537) (GenBank accession number NM_001792). The actin and glyceraldehyde-3-phosphate dehydrogenase (GAPDH) primer sets were purchased from Stratagene (La Jolla, CA).

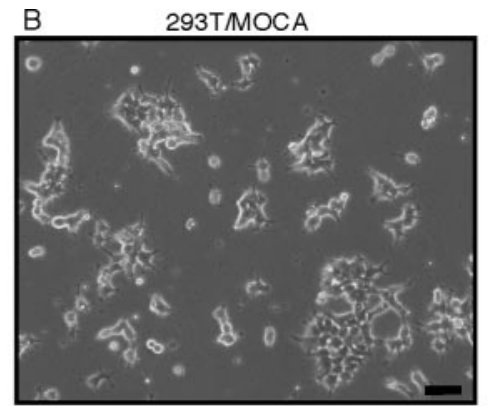

B103 E

E PC12
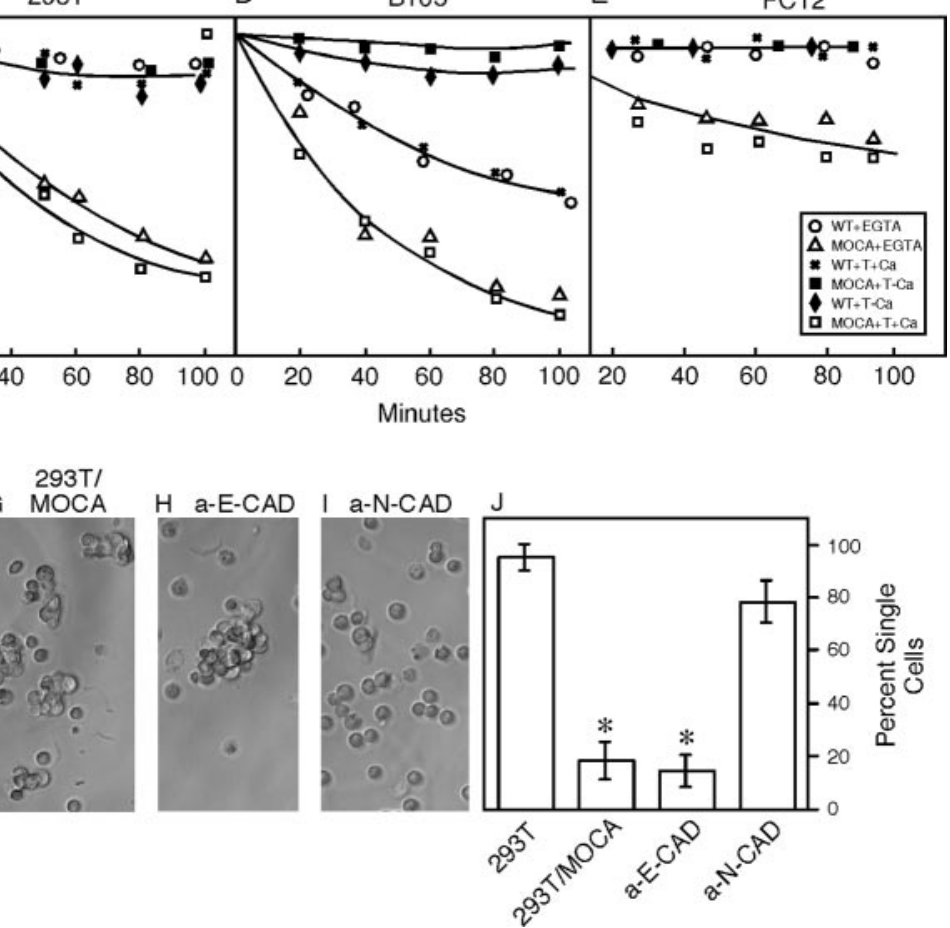

Figure 1. MOCA-induced cell-cell aggregation is calcium dependent, trypsin sensitive, and N-cadherin dependent. $A, B$, Phase-contrast images of 293T cells expressing MOCA or no MOCA. C, D, Three cell lines transfected with either MOCA or empty plass in the presence of $5 \mathrm{~mm}$ calcium by the disappearance of single cells as a function of time at $37^{\circ} \mathrm{C} . C, 293 \mathrm{~T}$ cells. D, B103 cells. E, PC12 cells. $\bigcirc$, Wild-type (WT) cells dissociated by EGTA; $\triangle$, MOCA-expressing cells dissociated with EGTA; X-X, wild-type cells dissoci列 with trypsin minus calcium; - MOCA cells dissociated with trypsin minus calcium. Scale bar, $25 \mu \mathrm{m}$. F--J, 293T cells ( F) or 293T cells expressing MOCA $(G)$ were dissociated with EGTA and allowed to reaggregate in the presence of anti-E-cadherin (a-E-CAD) $(H)$ or anti-N-cadherin (a-N-CAD) ( $/$ ). The data are quantitated in $J$. ${ }^{*}$ Significantly different from 293T control; $p<0.05$.

Cell aggregation assay. Cells with or without MOCA were plated at $1 \times$ $10^{6}$ per $100 \mathrm{~mm}$ dish and cultured overnight. Cells were washed with $\mathrm{Ca}^{2+}$ and $\mathrm{Mg}^{2+}$ free HEPES-buffered DMEM and treated in $\mathrm{Ca}^{2+}$ and $\mathrm{Mg}^{2+}$ free DMEM plus $0.1 \%$ trypsin plus or minus $5 \mathrm{mM} \mathrm{Ca}^{2+}$ for 30 min to disrupt cell-cell contacts. The cells were then washed in $0.5 \%$ soybean trypsin inhibitor and the rate of aggregation determined at $37^{\circ} \mathrm{C}$ with shaking in $2 \%$ bovine serum albumin-HEPES-buffered DMEM plus $\mathrm{Ca}^{2+}$. Single cells were counted as a function of time by using a Coulter particle counter (Beckman Instruments, Fullerton, CA). The data were plotted as the percentage of single cells relative to total single cells at zero time and are presented as the average of determinations from three different experiments.

Antibody blocking. In some cases, rabbit antisera against the extracellular domain of N-cadherin (H-63; Santa Cruz Biotechnology) or E-cadherin (H108; Santa Cruz Biotechnology) were used to inhibit aggregation or neurite outgrowth. In both cases, cells were dissociated in $\mathrm{Ca}^{2+}, \mathrm{Mg}^{2+}$-free culture medium with $0.5 \mathrm{~mm}$ EGTA at $37^{\circ} \mathrm{C}$ for $30 \mathrm{~min}$. The cells were then washed twice with $\mathrm{Ca}^{2+}, \mathrm{Mg}^{2+}$-free medium and 

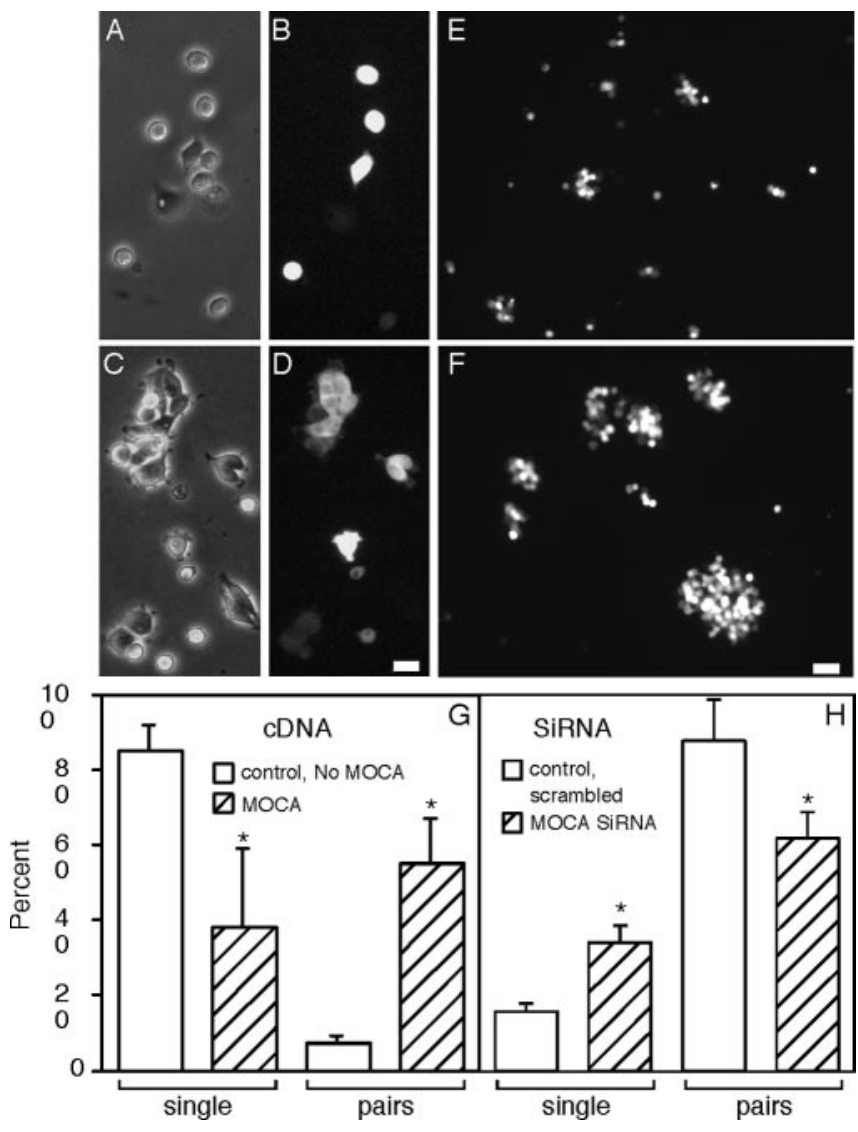

Figure 2. Transient transfection with MOCA increases cell-cell aggregation. 293T cells were transfected with MOCA or empty plasmid and a plasmid harboring the full-length GFP gene (ratio 10:1). Thirty hours later, the cells were dissociated with EGTA and allowed to aggregate. At 0 and $2 \mathrm{~h}$, the cells were plated on polylysine-coated dishes. Two hours later, they were scored for single fluorescent cells or for two or more fluorescent cells in contact as a percentage of the total fluorescent cells. $A$, Control, phase contrast. $B$, Control, fluorescent cells. C, MOCA, phase contrast. D, MOCA, fluorescent cells. G, Quantitation of above. Pairs indicate groups of two or more fluorescent cells, whereas singles indicate isolated single cells. Only fluorescent cells were scored. In some cases, MOCA-expressing 293T cells were transfected with the MOCA503i shRNA construct coexpressing GFP $(E)$ or the control shRNA construct $(F)$ for $3 \mathrm{~d}$ and aggregation determined as described above and quantified $(H)$. Note that the magnification in $E$ and $F$ is much lower than in $A-D$. Scale bars: $D, 10 \mu \mathrm{m} ; F, 25 \mu \mathrm{m}$. ${ }^{*} p<0.01$, significantly different from controls.

incubated with $40 \mu \mathrm{g} / \mathrm{ml}$ of the antisera for $15 \mathrm{~min}$. The cells were then spun down in complete $\mathrm{N} 2$ medium to assay aggregation $\left(1 \times 10^{6}\right.$ cells per $\mathrm{ml}$ ) $30 \mathrm{~min}$ later or replated on polylysine-coated or serum-free medium-coated 24 -well plates $\left(2 \times 10^{4}\right.$ cells per well in $\left.0.2 \mathrm{ml}\right)$ in the presence of antibody to measure neurite length $18-48 \mathrm{~h}$ later. Neurite length was determined using an eyepiece micrometer, and at least 100 neurites were measured. The data are presented as the mean \pm SEM.

Immunostaining. All cells except PC12 were fixed in 4\% paraformaldehyde in PBS for 20 min and washed three times with PBS. They were then permeabilized with $0.2 \%$ Triton X-100 and blocked in $10 \%$ normal goat serum in PBS solution for $1 \mathrm{~h}$ and incubated for $1 \mathrm{~h}$ with primary antibodies followed by fluorescent-conjugated secondary antibody (Molecular Probes, Eugene, OR). In some cases, rhodamine-phalloidin was included with the primary antibody. The cells were mounted under glass coverslips with antifading media containing $4 \% \mathrm{~N}$-propyl gallate (Sigma-Aldrich) and then examined with a Zeiss laser scanning microscope (Zeiss, Thornwood, NY).

PC12 cells, stably transfected to express MOCA, were cultured on glass coverslips for $3 \mathrm{~d}$ in $50 \mathrm{ng} / \mathrm{ml} \mathrm{NGF}$ and fixed for $20 \mathrm{~min}$ at $37^{\circ} \mathrm{C}$ with $4 \%$ paraformaldehyde in PBS. The fixed cells were blocked for $1 \mathrm{~h}$ in PBS with $0.1 \%$ Triton X-100 and 10\% normal goat serum. Anti-MOCA an- tibodies were diluted 1:100 in the blocking buffer and applied to cells for $1 \mathrm{~h}$ at room temperature. Rhodamine-phalloidin $(1 / 20)$ was included in the buffer with the primary antibody. After rinsing the coverslips and soaking them in the blocking solution for $1 \mathrm{~h}$, Alexa488-goat anti-rabbit antibodies diluted 1:800 in blocking buffer were applied to the coverslips for $1 \mathrm{~h}$ at room temperature.

Differential detergent fractionation. Differential detergent fractionation (DDF) is a standard protocol widely used to partition cellular proteins into structurally and functionally distinct compartments (Ramsby and Makowski, 1999). Cells were sequentially extracted through three different detergents (digitonin/EDTA, Triton X-100/EDTA, and Tween 40/deoxycholate), and finally detergent-resistant proteins were dissolved in SDS. Four cellular fractionations are identified following the Ramsby and Makowski (1999) procedure: cytosolic proteins in the digitonin fraction, membrane-organelle proteins in the Triton X-100 fraction, nuclear proteins in the Tween 40 fraction, and cytoskeletal-matrix proteins in the detergent-resistant (SDS) fraction.

Image analysis. The morphology of the cells was quantified by using a combination of image analysis methods (Costa et al., 2000, 2002; Costa and Cesar, 2001; Costa, 2003). Briefly, the contour of each cell was isolated from the image background by using adaptive thresholding and contour mapping (Costa and Cesar, 2001), resulting in a contour represented in Figure $7 A$, from which the list of the border element coordinates $b(x, y)$ was obtained. These coordinates were used to calculate the distance transform and the skeleton of each cell, as illustrated in Figure 7, $B$ and $C$, respectively. Because the distance transform value at any point $(x, y)$ inside or around the neuron corresponds to the smallest distance between that point and any of the contour elements, its skeleton provides an accurate representation of the cell morphology. Several determinant geometrical properties of each neuron can be accurately quantified from its distance transform and skeleton. The identification of the soma was critical and obtained by superposing circles along the skeleton portion near its main branch point with radii corresponding to the distance transform at those points. Figure $7 D$ illustrates the soma identified for the cell in A. Although the extremity of each branch was determined by looking for skeleton points with just one neighbor, the ramification points were identified as points having more than two neighbors. The arc-length distance from each extremity and ramification points to the starting point at the soma were then determined by using the Fourier transform-based method (Costa and Cesar, 2001). The arc-length distance from a branch (or extremity) point to the soma can be understood as the shortest path while moving along the respective neuronal processes, from that point toward the soma. The concept of arc-length distance is shown in Figure $7 E$, which is a schematic nerve cell containing soma, three extremity points (c, d, and e), as well as one branch point (b). Although the Euclidean distance of the extremity point $c$ to the soma corresponds to the length $\mathrm{d}$, the arc-length distance is defined as the length of the neurite through branch point $b$. The arc-length distance from branch points are typically smaller than for extremity points. The superiority of this type of measurement is clearly illustrated for the case of the neurite with extremity point e which, although far away from the soma in arc-length distance (along with neurite), is rather close in terms of the Euclidean distance e. Attention has consequently been focused on developing accurate computational methods for quantifying the biologically more relevant arc-length distance. These measurements, which provide valuable information about the neuronal morphology, were used to characterize cells expressing MOCA relative to controls.

\section{Results}

\section{MOCA promotes cell-cell adhesion}

Members of the DOCK180 family are involved in modulating cell adhesion and motility. Because MOCA is highly related to DOCK180, it is possible that MOCA is also involved in cell adhesion and morphology in a manner that is independent of its effect on APP expression. We therefore wanted to determine whether MOCA expression alters cell-cell adhesion and nerve cell shape. Initially, the morphological difference between cells expressing MOCA or no MOCA was examined under normal growth con- 
ditions using both neuronal and fibroblast cell lines. HEK293T cells do not synthesize endogenous MOCA and, when stably transfected with MOCA, they form cellular aggregates compared with the cells without MOCA (Fig. $1 A, B$ ). This effect of MOCA is also seen in the rat central nervous cell line B103 and PC12 sympathetic-like nerve cells (data not shown). B103 cells do not express endogenous MOCA, whereas PC12 cells express very low levels of MOCA (see Fig. 5C) in the absence of NGF. MOCAinduced cell-cell aggregation was further quantified in these three cell lines.

Cadherin-dependent adhesion was originally defined as being trypsin resistant in the presence of $\mathrm{Ca}^{2+}$ and trypsin sensitive in the absence of $\mathrm{Ca}^{2+}$ (Takeichi, 1995). 293T, B103, or PC12 cells stably transfected MOCA or with empty plasmid were dissociated with trypsin in the presence or absence of calcium, and the rate of aggregation was measured by the disappearance of single cells as a function of time at $37^{\circ} \mathrm{C}$ in the presence of $\mathrm{Ca}^{2+}$. When wildtype $293 \mathrm{~T}$ or PC12 cells are dissociated by trypsin in the presence or absence of $\mathrm{Ca}^{2+}$, the cells do not aggregate (Fig. 1C,E). In contrast, 293T or PC12 cells expressing MOCA aggregate when dissociated by trypsin in the presence of $\mathrm{Ca}^{2+}$ but do not aggregate when the cells are dissociated by trypsin in the absence of $\mathrm{Ca}^{2+}$, consistent with a cadherin-dependent adhesion (Takeichi, 1995). To determine the overall ability of cells to reaggregate in the absence of trypsin dissociation, which could destroy other cell-surface adhesion proteins, cells were dissociated with the calcium chelator EGTA and allowed to reaggregate. Wild-type cells dissociated with EGTA do not aggregate, whereas those expressing MOCA aggregate. Similar results were seen in the B103 nerve cell line, with the exception that wild-type B103 cells aggregated more slowly than B103 cells expressing MOCA after trypsin dissociation in the presence of $\mathrm{Ca}^{2+}$, showing that they do have some inherent cadherin-dependent adhesion (Fig. 1D). Because B103 cells do not synthesize APP (Schubert et al., 1989), this experiment rules out a potential requirement for APP in MOCAdependent aggregation.

Although Figure 1 shows that MOCA promotes aggregation in cell lines stably expressing MOCA, it is important to determine whether cells transiently transfected with MOCA exhibit a similar phenotype, because the selected clones may not be representative of the population. Because the transfection efficiency of PC12 cells is very low, and they aggregate relatively poorly even when expressing MOCA, and because B103 cells spontaneously aggregate, $293 \mathrm{~T}$ cells were used for this experiment. The $293 \mathrm{~T}$ cells are transfected with an efficiency between 40 and $60 \%$ as assayed by fluorescence-activated cell sorting with a GFP expression plasmid. The aggregation of transiently transfected cells was determined by cotransfecting cells with MOCA or empty expression plasmid and plasmid expressing enhanced GFP as a marker. After $30 \mathrm{~h}$, cultures were dissociated into single cells with EGTA and allowed to aggregate in complete medium as described in Figure 1. After $1 \mathrm{~h}$, cells from the aggregating cultures were plated on polylysine-coated culture dishes and allowed to adhere and spread on the very adhesive surface, thus preventing additional aggregation and "fixing" aggregates as groups of cells. After another $2 \mathrm{~h}$, the cultures were scored for single green fluorescent cells or fluorescent cells in groups of two or more. The data are presented as the percentage of total labeled (transfected) cells that are either single or in groups. Figure 2, $A-D$ and $G$, shows that there is a much greater frequency of single cells in the absence of MOCA than in its presence, and that MOCA expression increases the frequency of fluorescent groups of cells. These results support those obtained with stably transfected cell lines (Fig. 1).

\section{MOCA-induced cell-cell adhesion is associated with the increased expression of $\mathrm{N}$-cadherin}

At least 90 different cadherins have been identified or proposed through gene isolation and GenBank data analysis (Yagi and Takeichi, 2000). The levels of the two most common cadherins expressed in the nervous system were determined by Western blotting of B103, PC12, and 293T cell lysates expressing MOCA or no MOCA (Fig. 3A). E-cadherin is not expressed in B103 cells but is expressed in HEK293T and to a lesser extent in PC12 cells. In both cases, MOCA expression causes a decrease in expression. $\mathrm{N}$-cadherin is relatively abundant in B103 cells, whereas there is very little in 293T cells and even less in PC12 cells. In contrast, there is a high level of $\beta$-catenin, $\alpha$-catenin, $\gamma$-catenin, p120catenin, and desmoglein expression in all three types of cells. The expression level of $\mathrm{N}$-cadherin is elevated in all three types of cells when MOCA is expressed (Fig. 3A). The expression level of $\beta$-catenin was increased to a lesser extent by MOCA in B103 and 293 T cells and was not significantly altered in PC12 cells. Levels of $\alpha$-catenin, $\gamma$-catenin, and desmoglein were not increased by MOCA. A different expression pattern of p120catenin was also seen in $293 \mathrm{~T}$ cells expressing MOCA compared with 293T control cells. These data show that cell-cell adhesion is increased when the expression of $\mathrm{N}$-cadherin is enhanced by MOCA.

To establish whether or not $\mathrm{N}$-cadherin mediates the increased cell-cell aggregation following MOCA expression, 293T cells expressing MOCA or no MOCA were dissociated with EGTA and allowed to aggregate in the presence of antibodies against the extracellular domains of N- or E-cadherin. Antisera have been shown previously to block cadherin-dependent adhesion (Garcia-Castro et al., 2000). Figure $1 F-J$ shows that while 293T/MOCA cells spontaneously aggregate alone (Fig. $1 G$ ) or in the presence of anti-E-cadherin (Fig. $1 H$ ), anti-N-cadherin efficiently inhibited aggregation (Fig. 1I). These data are summarized in Figure $1 \mathrm{~J}$.

It could be argued that the increased $\mathrm{N}$-cadherin expression is attributable to the increased cell-cell adhesion caused by MOCA rather than MOCA increasing $\mathrm{N}$-cadherin expression, because it has been reported that increased cell-cell contacts and increased cell density positively alter the expression of cadherins (Dietrich et al., 2002). To address this point, we examined N-cadherin expression as a function of time after the disruption of cell-cell contacts by EGTA and plating at a low cell density. The disruption of cell-cell contacts reduced the initial N-cadherin expression in control cells but it gradually increased to normal levels (Fig. $3 B$ ). However, the expression of $\mathrm{N}$-cadherin in cells expressing MOCA was relatively unaffected by dissociation (Fig. 3B). Thus, the enhanced expression of N-cadherin by MOCA is not caused by an increase in cell-cell interactions.

To verify the specificity of the effects of MOCA on N-cadherin expression, RNA interference analysis was used to knock down MOCA expression. Six 21-nucleotide sequences targeting the MOCA gene were selected and used for making small interfering RNA (siRNA) duplexes. siRNA duplexes were transfected into cells expressing MOCA, and 72 and $96 \mathrm{~h}$ after transfection, the expression of MOCA and N-cadherin were assayed by Western blot analysis. Among the six siRNA duplexes tested, only two significantly lowered MOCA expression. They were named MOCA503i and MOCA5697i, respectively (Fig. 3C). Lowering the expression of MOCA also reduced the expression of $\mathrm{N}$-cadherin (Fig. 3C). The siRNA MOCA503i is best at lowering MOCA expression, and the corresponding DNA sequence was inserted into an shRNA plasmid vector, pSilencer2.1-U6 hygro, to 
A

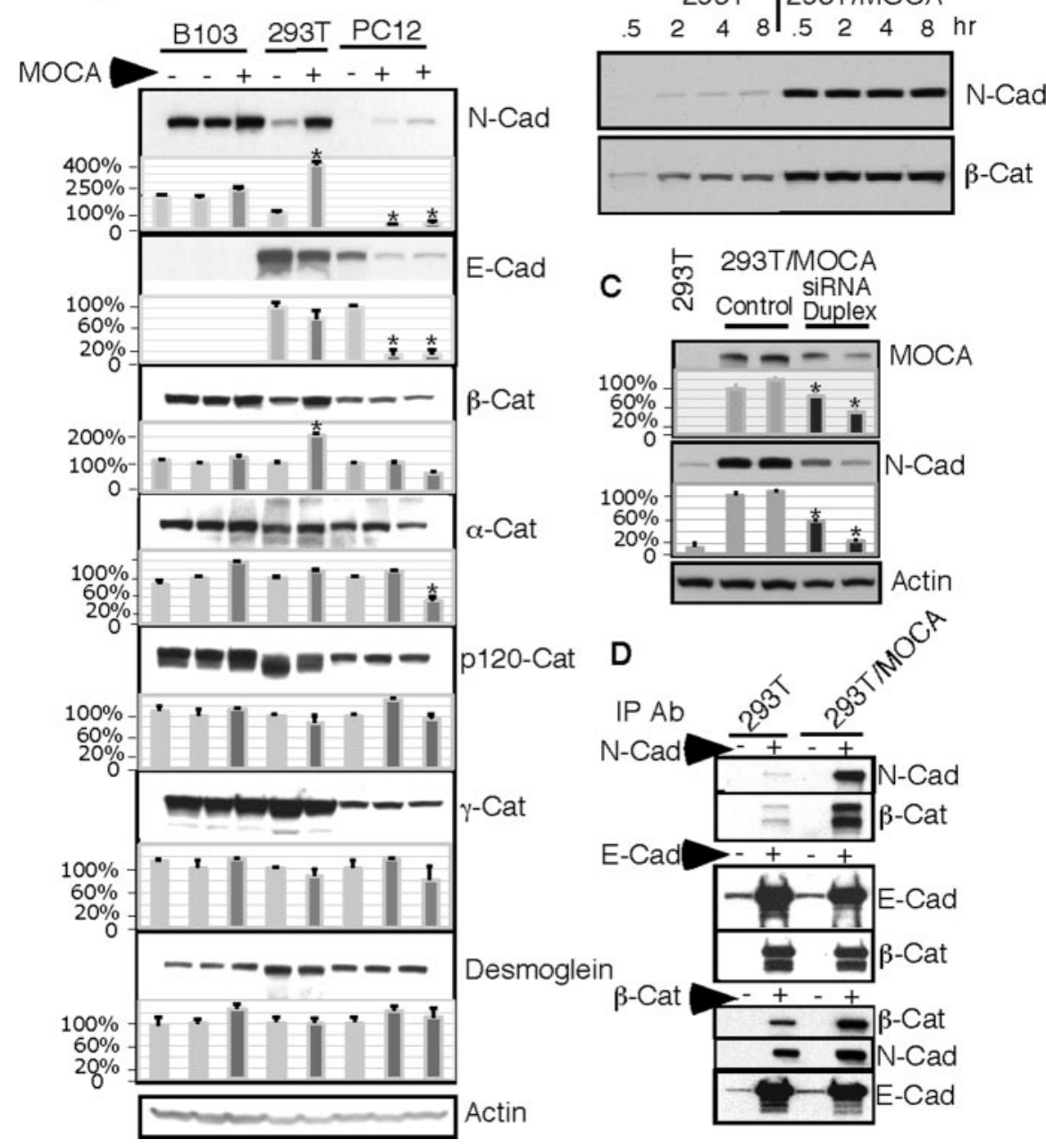

Figure 3. MOCA increases the expression levels of N-cadherin. $A$, Effect of MOCA on the level of protein components of the cell-cell adhesion system. Cells with or without MOCA were lysed, and the same amount of protein from the same type of cell was subjected to Western blot analysis. Actin was used as a loading control. B, MOCA-induced N-cadherin expression is not affected by cell density. Calcium was depleted by treating cells with $1 \mathrm{~mm}$ EGTA for $30 \mathrm{~min}$, resulting in a single-cell suspension. N-cadherin expression in cells expressing MOCA or no MOCA was examined by Western blotting as a function of time. C, Lowering MOCA by RNA interference also lowers $\mathrm{N}$-cadherin expression. siRNA duplexes targeting specific MOCA sequences were transfected into cells. Ninety-six hours after transfection, the expression of MOCA and N-cadherin was assayed by Western blot analysis. The expression of $\mathrm{N}$-cadherin was altered by RNA interference of MOCA gene expression as indicated by Western blotting. Actin was used as a loading control. Lane 1, 293T; lanes 2 and 3, 293T/MOCA, treated with scrambled siRNA duplexes; lanes 4 and 5, 293T/MOCA, treated with a MOCA siRNA duplex. D, MOCA increases the formation of N-cadherin and $\beta$-catenin complexes. Cell lysates extracted from 293T cells expressing MOCA or no MOCA were immunoprecipitated with the indicated antibodies (left) and/or beads alone. The resulting precipitates were then analyzed by Western blotting with the corresponding antibodies indicated on the right. The quantitation of protein expression was determined after normalized to the actin control by measuring the optical density of respective blots using NIH Image and presented as the percentage of change \pm SEM $(n=3) .{ }^{*} p<0.01$, significantly different from controls. The data are representative of three independent experiments. Ab, Antibody; E-Cad, Ecadherin; $\mathrm{N}$-Cad, N-cadherin; $\alpha$-Cat, $\alpha$-catenin; $\beta$-Cat, $\beta$-catenin; p120-Cat, p120-catenin; $\gamma$-Cat, $\gamma$-catenin. make a specific shRNA construct. We further modified this shRNA construct to coexpress GFP.

To determine whether the selective reduction of $\mathrm{N}$-cadherin by MOCA siRNA reduced cell-cell adhesion, MOCA 293T cells were treated for $3 \mathrm{~d}$ with the GFP-MOCA503i shRNA construct or the control GFP shRNA construct and the rate of adhesion determined. Figure 2, $E, F$, and $H$, shows that the downregulation of MOCA reduces cell-cell adhesion. These data suggest that the effect of MOCA on N-cadherin expression and cell-cell adhesion is specifically associated with the accumulation of MOCA.

Because the expression levels of both $\mathrm{N}$-cadherin and $\beta$-catenin were altered by MOCA, and because it is known that $\mathrm{N}$-cadherin and $\beta$-catenin form a complex important for assembling adherens junctions, we determined whether the complex formation between $\mathrm{N}$-cadherin and $\beta$-catenin was affected by MOCA. The association between $\mathrm{N}$-cadherin and $\beta$-catenin was increased by MOCA in proportion to MOCA expression as indicated by co-IP (Fig. 3D). In contrast, the association of $\beta$-catenin and E-cadherin was not affected by the expression of MOCA. These data indicate that MOCA increases complex formation between $\mathrm{N}$-cadherin and $\beta$-catenin. We did not consistently observe any interactions by co-IP experiments. Therefore, it is likely that there is a yet to be identified intermediate for which expression or function is modified by MOCA. Alternatively, the conditions used in the coimmunoprecipitation experiments might not favor these interactions.

The mechanism underlying the effect of MOCA on N-cadherin expression was examined by Northern blotting and a pulse-chase experiment. In Northern blot analysis, a strong $4.3 \mathrm{~kb}$ band with two minor bands, 5.3 and $3.5 \mathrm{~kb}$, respectively, was observed (Miyatani et al., 1989) (Fig. 4A). The level of the major $\mathrm{N}$-cadherin mRNA transcript is not affected by MOCA, but one of the minor transcripts is altered in cells expressing MOCA. RT-PCR was done to verify the Northern blot data, showing that the level of $\mathrm{N}$-cadherin mRNA is not affected by MOCA (Fig. 4B). N-cadherin stability was assayed by pulse-chase analysis. In cells expressing MOCA, the level of newly synthesized N-cadherin decreases less rapidly compared with cells with no MOCA (Fig. 4C). These data suggest that MOCA increases $\mathrm{N}$-cadherin expression at least partly by increasing its stability.

MOCA localizes to the cytoplasm and, to a lesser extent, to membranes of $293 \mathrm{~T}$ cells (Kashiwa et al., 2000). Because cadherins are membrane proteins and their functions are mediated through homophilic interactions at the cell surface, it was determined whether MOCA expression increases the expression of $\mathrm{N}$-cadherin at the cell membrane. The expression of E-cadherin, $\mathrm{N}$-cadherin, and $\beta$-catenin in the cell membrane of 293T cells was determined by both immunostaining and cell fractionation (Fig. 4). In the absence of MOCA, there is a very low level of N-cadherin in the cell membrane, although there was a significant level for $\beta$-catenin. However, in the presence of MOCA, the levels of both N-cadherin and $\beta$-catenin are increased in the membrane at areas of cell-cell contact (Fig. 4D). No difference in the staining pattern of E-cadherin was seen in cells in response to MOCA expression, and E-cadherin was predominantly seen in a punctuated pattern, consistent with previous observations (Tomschy et al., 1996). 
DDF was also used to examine the cellular localization of MOCA and the components of cell adherens junctions and the cytoskeleton. 293T cells were sequentially extracted with digitonin, Triton X-100, Tween 40, and SDS to yield cytosolic, membrane, nuclear, and cytoskeletal proteins, respectively (Ramsby and $\mathrm{Ma}$ kowski, 1999). Control proteins showed the expected distribution (Fig. 4E). MOCA is expressed in the cytoplasmic, cytoskeletal, and membrane-organelle fractions but not in the nuclear fraction. Although very little $\mathrm{N}$-cadherin was detected in the cytoplasmic fraction, it was found in all of the other three fractions. Its presence in the nuclear fraction requires additional investigation. As with total cell extracts, $\mathrm{N}$-cadherin was greatly increased in cells expressing MOCA relative to cells without MOCA, whereas E-cadherin was found in all four fractions, and this was not significantly affected by MOCA expression. The level of $\beta$-catenin was enhanced in membrane and cytoskeletal fractions by MOCA but remained constant in the cytoplasm. $\gamma$-catenin showed an expression pattern similar to E-cadherin, and p120catenin was preferentially expressed in the cytoplasmic and membrane-organelle fractions and, to a less extent, in the other two fractions. The level of p120catenin in the cytoplasmic fraction was significantly decreased by MOCA. The cellular localization of cadherins and catenins was consistent with their biological functions and with previous observations (Tomschy et al., 1996).

\section{MOCA expression alters cell morphology}

The above data show that the expression of MOCA upregulates $\mathrm{N}$-cadherin expression and promotes $\mathrm{N}$-cadherin-mediated adhesion. The expression of $\mathrm{N}$-cadherin has also been linked to nerve cell morphology, including neurite outgrowth (Utton et al., 2001). We therefore determined whether MOCA expression increases $\mathrm{N}$-cadherin secretion and subsequent adsorption to the tissue culture plastic to enhance neurite outgrowth. It has been shown that proteins secreted from cells adsorb to tissue culture plastic to form substrate-attached material (SAM), which can mediate cell-substratum adhesion (Cole et al., 1985).

PC12 cells express a very low level of MOCA in the absence of NGF, and stable transfection of PC12 cells with MOCA does not induce neurite outgrowth in the absence of NGF (data not shown). However, the expression of MOCA does increase the secretion of $\mathrm{N}$-cadherin in all three cell types examined (PC12, B103, and 293T) (Fig. 4F). To determine whether N-cadherin has

$\beta$-Catenin
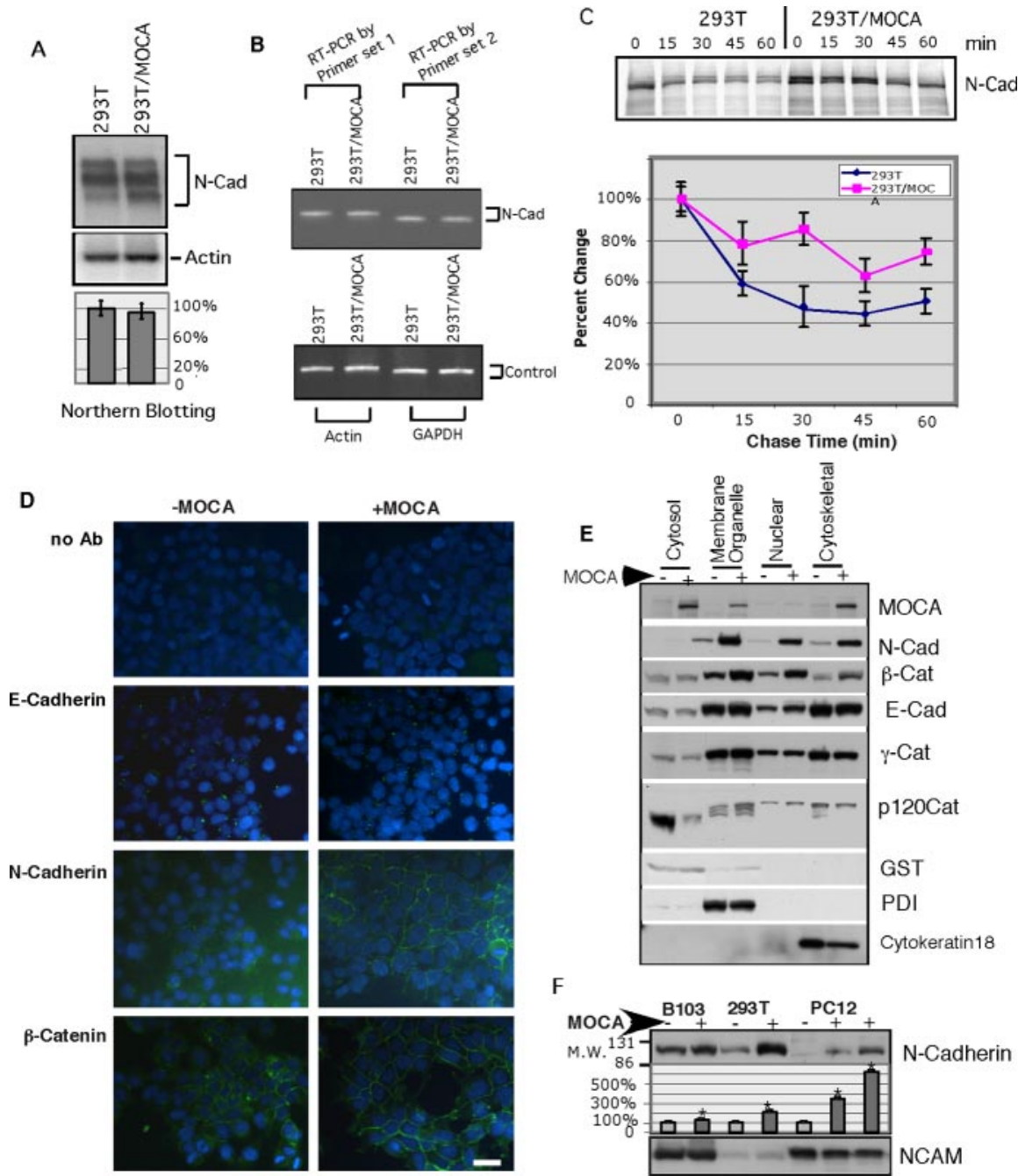

F

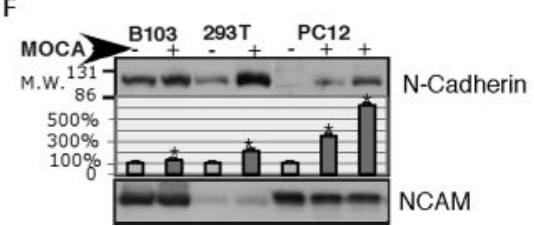

Figure 4. The level of $\mathrm{N}$-cadherin mRNAs and the turnover rate, immunostaining pattern, and cellular fractionation of $\mathrm{N}$-cadherin in cells expressing MOCA or no MOCA. A, Northern blot hybridization of N-cadherin mRNA in 293T cells expressing MOCA or no MOCA. The quantitation of the major N-cadherin band was determined after normalization to the actin control. The data are presented as the percentage of change \pm SEM. $B, R T-P C R$ of N-cadherin was performed using two different primer sets as described in Materials and Methods. Actin and GAPDH were used as control. C, The turnover rate of newly synthesized N-cadherin in 293T cells expressing MOCA or no MOCA. The optical density of N-cadherin expression was quantified by NIH Image, and the data are presented as the percentage of change after being normalized to the initial level of newly synthesized N-cadherin. D, Immunostaining of E-cadherin, N-cadherin, and $\beta$-catenin in 293T cells expressing MOCA or no MOCA. E-cadherin, N-cadherin, and $\beta$-catenin were stained by their corresponding antibodies and visualized by fluorescein-labeled secondary antibodies (green). Nuclei were stained by $4^{\prime}, 6^{\prime}$-diamidino-2-phenylindole (blue). Cells expressing MOCA are in the right column and expressing no MOCA in the left column. Background staining with secondary antibody alone is also shown in the top panel. Scale bar, $10 \mu \mathrm{m}$. $E$, Detergent fractions of cell extracts were immunoblotted to MOCA, N-cadherin, E-cadherin, $\beta$-catenin, $\gamma$-catenin, and p120catenin. The localization of MOCA and adherens junction proteins were assayed by sequential extraction using different detergents as described in Materials and Methods. GST is the control for cytoplasm, PDI for membrane organelles, and cytokeratin 18 for the cytoskeletal-matrix fractions (Ramsby and Makowski, 1999). F, The secretion of N-cadherin was significantly enhanced by MOCA in B103, 293T, and PC12 cells, whereas the secretion of neural cell adhesion molecule (NCAM) was not affected by MOCA. The quantitation of $\mathrm{N}$-cadherin secretion was determined after normalization to the NCAM. The data are presented as the percentage of change $\pm \mathrm{SEM}(n=3)$. ${ }^{*} p<0.01$, significantly different from controls. Ab, Antibody; E-Cad, E-cadherin; N-Cad, $\mathrm{N}$-cadherin; $\beta$-Cat, $\beta$-catenin; p120Cat, p120-catenin; $\gamma$-Cat, $\gamma$-catenin.

a role in the determination of neurite morphology during the differentiation process, PC12 cells stably transfected with empty vector (Fig. 5A, control) or MOCA-Tag (Fig. 5B, MOCA) were treated with NGF for $2 \mathrm{~d}$, and the cells were then examined morphologically and by Western blotting using either anti-Tag or anti-MOCA antibodies. The overexpression of MOCA dramatically increases NGF-induced neurite length in PC12 cells. Figure $5 C$ shows that when the cells are treated with NGF, there is a large 
A Control + NGF
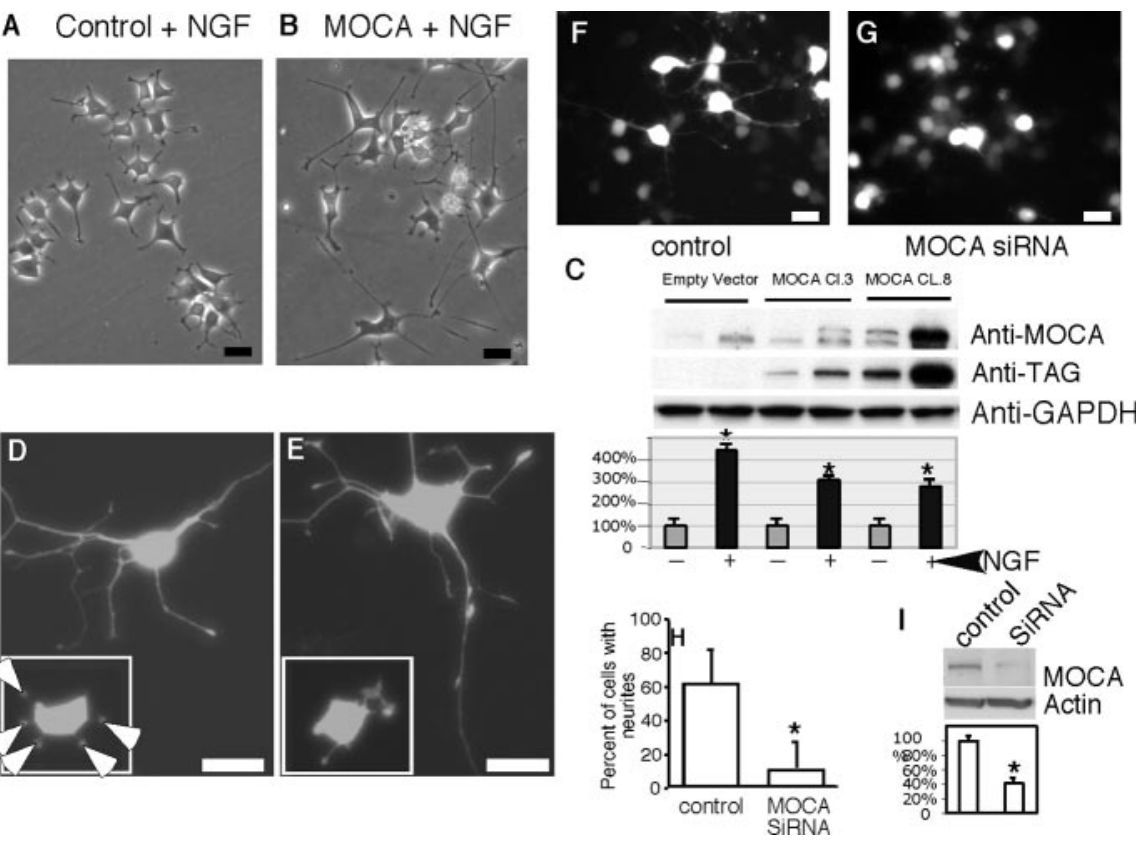
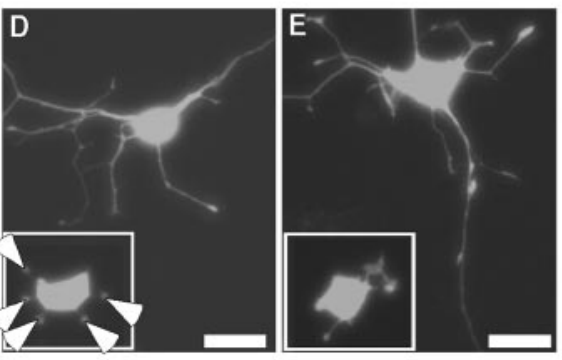

Figure 5. MOCA accumulates during NGF-induced differentiation. PC12 cells expressing no MOCA ( $A$; empty plasmid) or MOCA (B) were exposed to $100 \mathrm{ng} / \mathrm{ml} \beta$-NGF for $2 \mathrm{~d}$, lysed in SDS sample buffer, and equal amounts of protein loaded onto $10 \%$ SDS acrylamide gels. The samples were blotted with either anti-MOCA, anti-TAG, or anti-GAPDH antibodies ( $C$ ). The changes of MOCA expression by NGF were quantified by NIH Image. The data are presented as the percentage of change relative to the control without NGF treatment. PC12 cells with NGF $(D, E)$ or HCN cells were transfected with either the control shRNA construct $(F)$ or MOCA503i shRNA construct $(D, E$, insets, $G)$, and the percentage of cells with neurites greater than one cell body diameter was quantified $(H)$. The amount of MOCA in HCN cells was assayed after transfection ( $/$ ). Scale bar, $5 \mu \mathrm{m}$. The data are representative of three independent experiments. ${ }^{*} p<0.05$.

increase in the accumulation of both transfected (anti-Tag) and endogenous MOCA. Because the expression of the transfected MOCA cDNA is not under transcriptional control, these results show that both endogenous and transfected MOCA accumulate during the differentiation relative to other endogenous proteins such as GAPDH used as a control.

If MOCA is involved in determining neurite outgrowth, then the downregulation of MOCA in PC12 cells transfected with MOCA or in cells expressing high levels of endogenous MOCA should reduce the extent of outgrowth. Figure 5, $D$ and $E$, shows that transfection of PC12 cells expressing elevated levels of MOCA with the MOCA503i construct reduced neurite outgrowth dramatically. Reducing MOCA expression in cells expressing endogenous protein should also reduce neurite outgrowth. $\mathrm{HCN}$ is a rat hippocampal neuronal precursor cell line (Taupin et al., 2000) that expresses endogenous MOCA. When MOCA expression is reduced by the expression of MOCA503i shRNA construct (Fig. 5I), there is a corresponding reduction in the percentage of cells with neurites (Fig. $5 D, E$, insets, $H$ ). These data show that there is an intimate relationship between MOCA expression and neurite outgrowth.

To more formally establish a role of N-cadherin in MOCAenhanced neurite outgrowth, the ability of $\mathrm{N}$-cadherin-specific antiserum to block this effect was examined. PC12 cells transfected with MOCA have no neurites in the absence of NGF (Fig. $6 A$ ) but extend much longer neurites than wild-type cells in the presence of NGF (Figs. 5B, 6B). Although antisera against fibronectin has no effect on neurite outgrowth (Fig. 6C), Figure 6, $D$ and $H$, shows that anti-N-cadherin reduced neurite outgrowth to near control levels in cells expressing MOCA. To determine whether substrate-attached $\mathrm{N}$-cadherin is directly able to mediate neurite outgrowth, PC12 cells expressing MOCA were plated on plastic culture dishes coated with growth conditioned medium from $293 \mathrm{~T}$ or $293 \mathrm{~T}$ cells transfected with MOCA, which greatly enhances the secretion of N-cadherin (Fig. $4 C$ ). Figure $6 F$ shows that plating cells on $\mathrm{N}$-cadherin-coated substrate enhances NGF-induced neurite outgrowth in PC12 cells relative to cells plated on dishes containing less $\mathrm{N}$-cadherin (Fig. 6E). Figure $6 G$ shows that this effect is blocked by $\mathrm{N}$-cadherin antibody.

Figure 5, $A$ and $B$, shows extensive morphological differences between controls (vector alone) and MOCAtransfected PC12 cells after 2 d exposure to NGF. To determine any subtle difference between cells expressing higher levels of MOCA, a procedure, described in Materials and Methods, was used for the quantitation of a number of morphological parameters. Briefly, the contour of each cell was isolated (Fig. 7A) and a list of border elements obtained. These elements were used to calculate the distance transform (Fig. $7 B$ ) and the neuronal skeleton (Fig. 7C). Finally, the cell soma was defined (Fig. 7D) and used to quantify neurite length (Fig. $7 E$, arc-length distance, soma to e, d, c) and neuritic branch point to soma (Fig. $7 E$, soma to $b$ ). Figure 7 shows the relative frequency curves of arc-length distance from the branch point to the soma (Fig. $7 F$ ) and the arc-length distance from the extremity to soma (Fig. $7 G$ ), respectively. These data show that cells expressing MOCA have longer neurites and that the branch points are further from the soma. Therefore, MOCA expression can lead to quantitatively increased morphological complexity in terms of total neurite length per cell as well as the less obvious distance of the neurite branch point from the soma.

Because the actin cytoskeleton plays a major role in neurite and synaptic structure and activity (Gallo and Letourneau, 2004), we determined whether MOCA colocalizes with actin filaments. PC12 cells differentiated with NGF were costained with antiMOCA and rhodamine-phalloidin, which binds to polymerized actin (F-actin). Figure 8 shows that MOCA colocalizes with actin filaments in three regions where actin filaments are characteristically concentrated. MOCA and F-actin colocalize at cell-cell interfaces between adherent PC12 cells (Fig. $8 A--C$, arrows) and at cell-substrate contact sites (Fig. $8 D-F$, arrows). MOCA and actin also colocalize in growth cones at neurite tips and in growth cone-like protrusions from PC12 cell bodies. These observations support a role for MOCA in regulating cytoskeletal organization and dynamics in developing neurons, and they are consistent with the differential detergent fractionation analysis.

\section{Discussion}

MOCA is a DOCK180-related protein that reduces cellsubstratum adhesion by downregulating APP accumulation (Chen et al., 2002). This study shows that MOCA increases calcium-dependent cell-cell adhesion that is specifically mediated by $\mathrm{N}$-cadherin and that the effect of MOCA on cell-cell 

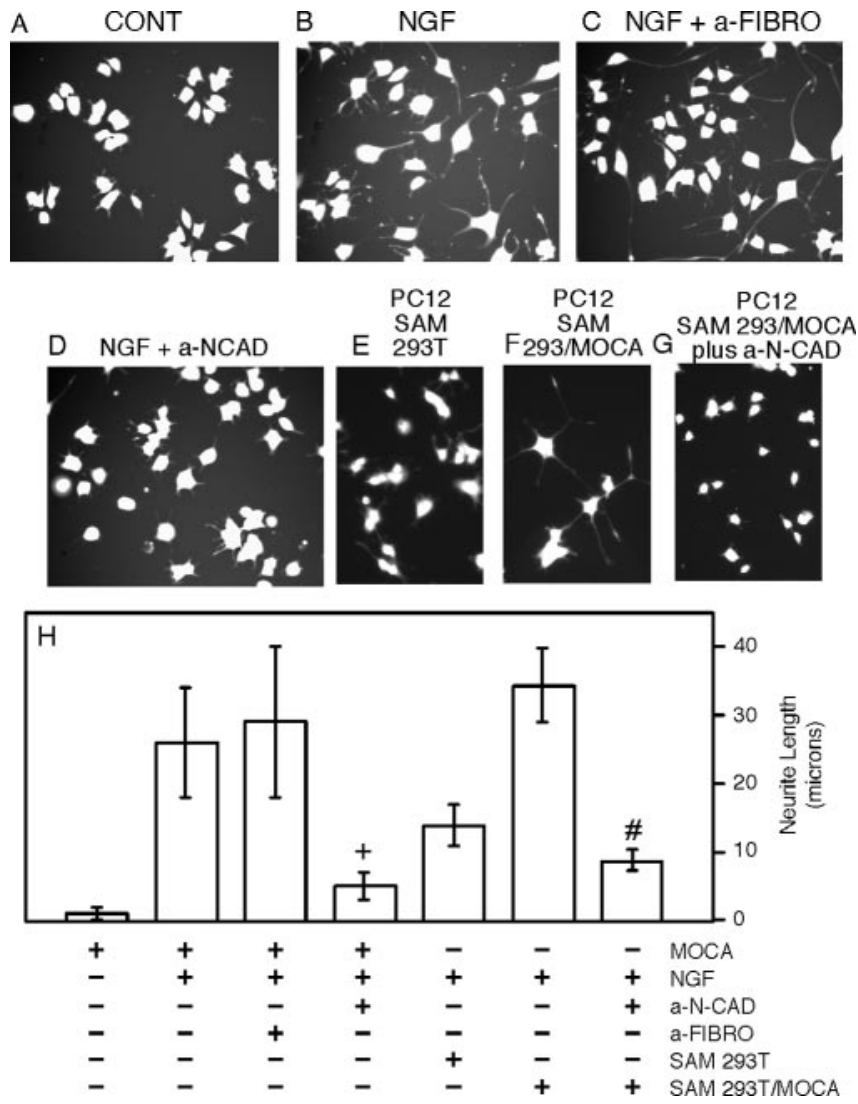

Figure 6. MOCA mediates neurite outgrowth. PC12 cells expressing or not expressing MOCA were dissociated with EGTA and treated with the various antibodies as described in Materials and Methods. Neurite outgrowth was scored either $24 \mathrm{~h}(E-G)$ or $48 \mathrm{~h}(A-D)$ later. In some cases, cells were plated on culture dishes coated for $24 \mathrm{~h}$ with conditioned serum-free medium from either 293T or 293T/MOCA cells in the presence or absence of antisera. A, PC12/MOCA cells, no NGF. B, PC12/MOCA cells treated with $100 \mathrm{ng} / \mathrm{ml}$ NGF. C, PC12/MOCA cells plus NGF exposed to anti-fibronectin (a-FIBRO). D, PC12/MOCA cells plus NGF exposed to anti-N-cadherin (aNCAD). E, PC12 cells plus NGF plus 293T-coated surface (SAM). F, PC12 cells plus 293T/MOCA SAM. G, PC12 cells, plus 293T/MOCA SAM plus anti-N-cadherin (a-N-CAD). H, Quantitation of neurite lengths. ${ }^{+}$Significant difference from MOCA plus NGF, $p<0.01$; ${ }^{*}$ significant difference from CM 293T/MOCA, $p<0.01$. CONT, Control.

adhesion is independent of APP expression. In addition, it is shown that MOCA is involved in neurite outgrowth.

When 293T, PC12, and B103 cells either expressing or not expressing MOCA are dissociated with trypsin plus or minus $\mathrm{Ca}^{2+}$ and allowed to aggregate in the presence of $\mathrm{Ca}^{2+}$, wild-type $293 \mathrm{~T}$ and PC12 cells do not aggregate with either dissociation condition, whereas cells expressing MOCA aggregate when dissociated in the presence of calcium but not in its absence. Similar results were obtained with the B103 cells except that there is some endogenous aggregation. MOCA-directed aggregation is $\mathrm{Ca}^{2+}$ dependent in both cases (data not presented) and can be inhibited by siRNA against MOCA. Therefore, cell aggregation caused by MOCA expression meets the criteria for cadherin-mediated adhesion (Takeichi, 1991).

The cadherins are a diverse group of cell adhesion molecules that contains at least 90 members (Yagi and Takeichi, 2000). Several cadherins can coexist in one cell type (Stewart et al., 2000), and the specificity of cell-cell adhesion is highly dependent on the types of cadherins expressed (Yagi and Takeichi, 2000; Charrasse et al., 2004). It is shown here that both E-cadherin and N-cadherin are expressed in $293 \mathrm{~T}$ cells, but only $\mathrm{N}$-cadherin expression is significantly increased by MOCA and that antisera against the extracellular domain of $\mathrm{N}$-cadherin blocks aggregation (Fig. 1). MOCA also increases N-cadherin expression in B103 and PC12 cells, and this effect is reversed by knocking down MOCA expression with specific MOCA siRNAs (Fig. 3), indicating that N-cadherin is a major molecular target regulated by MOCA. These data are consistent with the observation that the strength of cell-cell adhesion is associated with the expression levels of cadherins (Steinberg and Takeichi, 1994).

In addition to $\mathrm{N}$-cadherin, the $\beta$-catenin levels are slightly increased by MOCA in 293T and B103 cells, but the expression of desmoglein and $\gamma$-catenin, two major components of desmosomes, are not affected. Therefore, it is likely that MOCA only affects cadherin-mediated functions specifically associated with adherens junctions. Both Western blotting and immunostaining show that $\mathrm{N}$-cadherin and $\beta$-catenin levels are increased in the membranes of MOCA-expressing cells. Very little N-cadherin is detected in the plasma membrane of wild-type cells, whereas there is a considerable amount of $\beta$-catenin expression at the membrane, suggesting that $\beta$-catenin is present in the membrane before $\mathrm{N}$-cadherin. In contrast, the amount of E-cadherin in membranes does not increase following MOCA expression.

Immunoprecipitation data show that MOCA increases the amount of complex formation between $\mathrm{N}$-cadherin and $\beta$-catenin in proportion to $\mathrm{N}$-cadherin expression (Fig. 3), and pulse-chase data show that MOCA reduces the rate of $\mathrm{N}$-cadherin breakdown (Fig. 4). Complex formation is important for $\mathrm{N}$-cadherin-mediated cell-cell adhesion because the conformation of cadherins is changed after binding $\beta$-catenin to prevent their degradation (Huber and Weis, 2001; Huber et al., 2001). Stabilization of cadherins by $\beta$-catenin is required for their efficient transport to the plasma membrane (Chen et al., 1999). Because the affinity of $\beta$-catenin for cadherins is determined by phosphorylation states of $\beta$-catenin (Sommers et al., 1994; Muller et al., 1999; Roura et al., 1999; Piedra et al., 2001), MOCA may modulate $\beta$-catenin phosphorylation and therefore cause an alteration in complex formation. Alternatively, MOCA may be involved in the posttranslational modification of $\mathrm{N}$-cadherin.

The cadherins are widely expressed in the nervous system (Geiger and Ayalon, 1992), but the temporal expression pattern of each type is unique. These diverse patterns reflect the different adhesive properties required for different stages of development. $\mathrm{N}$-cadherin is highly expressed in the developing CNS, where it is involved in neuronal cell migration and cytoarchitectural development (Redies and Takeichi, 1996; Inoue and Sanes, 1997; Iwai et al., 1997). The overall levels of $\mathrm{N}$-cadherin are reduced in the adult brain, but $\mathrm{N}$-cadherin is concentrated in synaptic junctions and perhaps involved in synaptic modulation (Beesley et al., 1995; Fannon and Colman, 1996; Uchida et al., 1996; Benson and Tanaka, 1998; Redies, 2000; Tanaka et al., 2000). Transcriptional regulation is prevalent during development, but posttranslational alternations of $\mathrm{N}$-cadherins are more readily found in the adult (Tang et al., 1998; Tanaka et al., 2000).

The observation that MOCA increases $\mathrm{N}$-cadherin expression as well as neurite outgrowth in PC12 cells is consistent with the observation that MOCA increases $\mathrm{N}$-cadherin secretion (Fig. $4 C$ ), because both soluble and substrate-attached N-cadherin promote neurite outgrowth (Doherty et al., 1996; Utton et al., 2001). In contrast, the inhibition of endogenous MOCA expression in a hippocampal cell line and in PC12 cells transfected with MOCA dramatically reduces neurite outgrowth. MOCA is associated with F-actin in neurites and in areas of cell-substratum adhesion (Fig. 8), suggesting that in addition to having a function in cell-cell adhesion, MOCA may play a direct role in modulating 

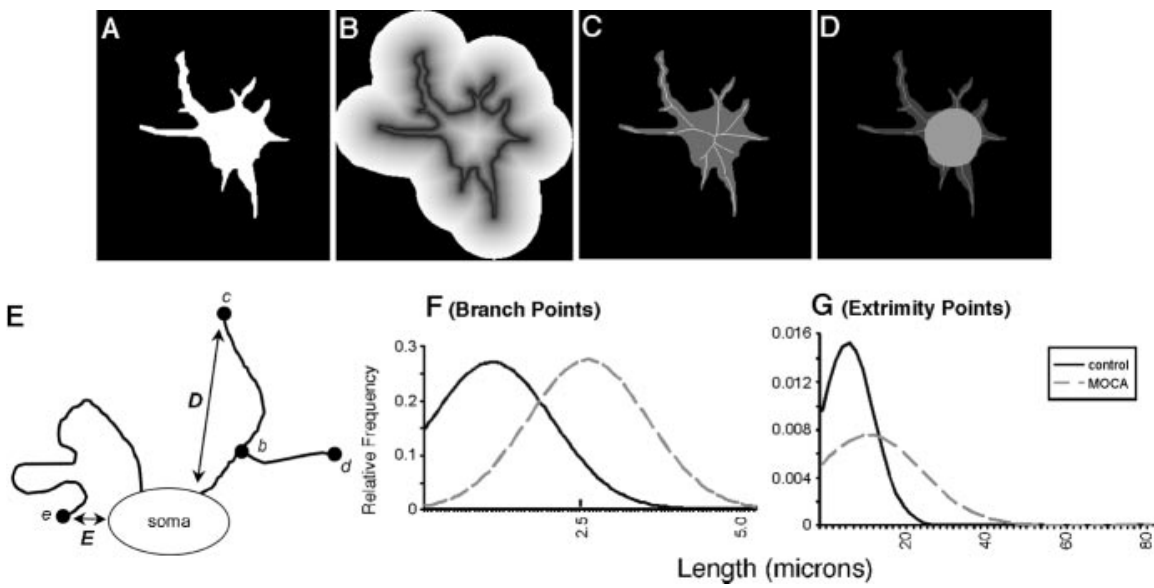

Figure 7. Image analysis of $\mathrm{PC} 12$ cells. A typical neuron shape $(A)$, its respective distance transform $(B)$, skeleton with branches $(C)$, and branch points $(D)$; schematic neuron used to define arc-length $(E)$, soma to e along neurite. $F$, Quantitation of arc-length distances from branch points to soma (length in micrometers). G, Quantitation of arc-length distances from extremity points to soma in micrometers. This experiment was repeated with three independent clones with similar results.
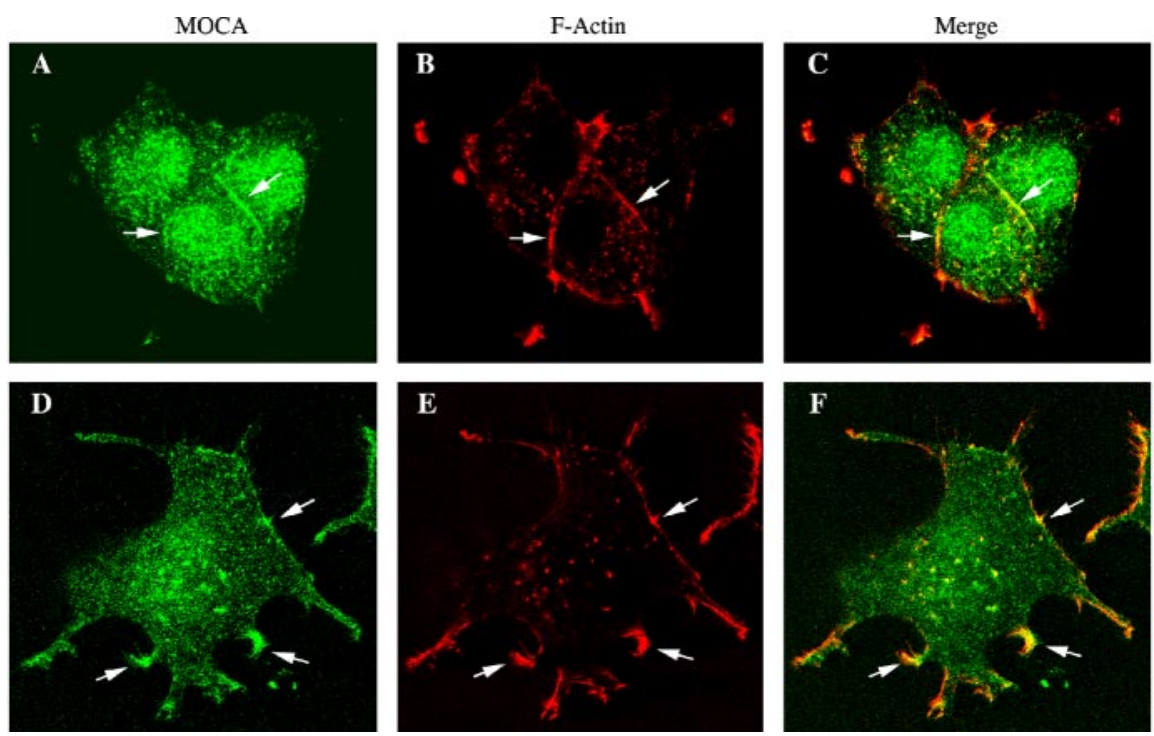

Figure 8. MOCA and F-actin colocalize at cell-cell interfaces and at the cell substrate level. MOCA-transfected PC12 cells were fixed and double labeled with anti-MOCA antibody and with rhodamine-phalloidin. In A-C,MOCA and F-actin are seen colocalized at cell-cell interfaces (arrows). In the merged image in $C$, areas of colocalization are yellow (arrows). In $D-F$, confocal images at the substratum level show colocalization of MOCA and F-actin at cell-substrate contacts (arrows) and within growth cones and filopodial tufts of cell bodies ( $D-F$, arrows). In the merged image in $F$, areas of colocalization are yellow.

the organization of the actin cytoskeleton during neuronal differentiation. Because MOCA is uniquely expressed in brain neurons and $\mathrm{N}$-cadherin is a major cadherin in the nervous system, MOCA may have a significant role in normal brain development and synaptic function.

\section{References}

Beesley PW, Mummery R, Tibaldi J (1995) N-cadherin is a major glycoprotein component of isolated rat forebrain postsynaptic densities. J Neurochem 64:2288-2294.

Benson DL, Tanaka H (1998) N-cadherin redistribution during synaptogenesis in hippocampal neurons. J Neurosci 18:6892-6904.

Brugnera E, Haney L, Grimsley C, Lu M, Walk SF, Tosello-Trampont AC, Macara IG, Madhani H, Fink GR, Ravichandran KS (2002) Unconventional Rac-GEF activity is mediated through the Dock180-ELMO complex. Nat Cell Biol 4:574-582.

Charrasse S, Comunale F, Gilbert E, Delattre O, Gauthier-Rouviere C (2004) Variation in cadherins and catenins expression is linked to both pro- liferation and transformation of rhabdomyosarcoma. Oncogene 23:2420-2430.

Chen Q, Yoshida H, Schubert D, Maher P, Mallory M, Masliah E (2001) Presenilin binding protein is associated with neurofibrillary alterations in Alzheimer's disease and stimulates tau phosphorylation. Am J Pathol 159:1597-1602.

Chen Q, Kimura H, Schubert D (2002) A novel mechanism for the regulation of amyloid precursor protein metabolism. J Cell Biol 158:79-89.

Chen YT, Stewart DB, Nelson WJ (1999) Coupling assembly of the E-cadherin/beta-catenin complex to efficient endoplasmic reticulum exit and basal-lateral membrane targeting of E-cadherin in polarized MDCK cells. J Cell Biol 144:687-699.

Cole GJ, Schubert D, Glaser L (1985) Cellsubstratum adhesion in chick neuronal retina depends upon protein-heparan sulfate interactions. J Cell Biol 100:1192-1199.

Costa Ld F (2003) Enhanced multiscale skeletons. J Real-Time Imaging 9:315-319.

Costa Ld F, Cesar Jr RM (2001) Shape analysis and classification: theory and practice. Boca Raton, FL: CRC.

Costa Ld F, Campos AG, Estrozi LF, Filho LGR, Bosco A (2000) A biologically motivated approach to image representation and its application to neuromorphology. Biol Motiv Comput Vis 1811:407-416.

Costa Ld F, Manoel ET, Faucereau F, Chelly J, Van Pelt J, Ramakers G (2002) A shape analysis framework for neuromorphometry. Network 13:283-310.

Cote JF, Vuori K (2002) Identification of an evolutionarily conserved superfamily of DOCK180related proteins with guanine nucleotide exchange activity. J Cell Sci 115:4901-4913.

de Silva MG, Elliott K, Dahl HH, Fitzpatrick E Wilcox S, Delatycki M, Williamson R, Efron D, Lynch M, Forrest S (2003) Disruption of a novel member of a sodium/hydrogen exchanger family and DOCK3 is associated with an attention deficit hyperactivity disorder-like phenotype. J Med Genet 40:733-740.

Dietrich C, Scherwat J, Faust D, Oesch F 2002 Subcellular localization of beta-catenin is regulated by cell density. Biochem Biophys Res Commun 292:195-199.

Doherty P, Smith P, Walsh FS (1996) Shared cell adhesion molecule (CAM) homology domains point to CAMs signalling via FGF receptors. Perspect Dev Neurobiol 4:157-168.

Fannon AM, Colman DR (1996) A model for central synaptic junctional complex formation based on the differential adhesive specificities of the cadherins. Neuron 17:423-434.

Gallo G, Letourneau PC (2004) Regulation of growth cone actin filaments by guidance cues. J Neurobiol 58:92-102.

Garcia-Castro M, Vielmetler E, Bonner-Fraser M (2000) N-cadherin, an adhesion molecule involved in establishment of left-right asymmetry. Science 288:1047-1051.

Geiger B, Ayalon O (1992) Cadherins. Annu Rev Cell Biol 8:307-332.

Grimsley CM, Kinchen JM, Tosello-Trampont AC, Brugnera E, Haney LB, Lu M, Chen Q, Klingele D, Hengartner MO, Ravichandran KS (2004) Dock180 and ELMO1 proteins cooperate to promote evolutionarily conserved Rac-dependent cell migration. J Biol Chem 279:6087-6097.

Huber AH, Weis WI (2001) The structure of the beta-catenin/E-cadherin complex and the molecular basis of diverse ligand recognition by betacatenin. Cell 105:391-402.

Huber AH, Stewart DB, Laurents DV, Nelson WJ, Weis WI (2001) The cadherin cytoplasmic domain is unstructured in the absence of beta- 
catenin. A possible mechanism for regulating cadherin turnover. J Biol Chem 276:12301-12309.

Inoue A, Sanes JR (1997) Lamina-specific connectivity in the brain: regulation by N-cadherin, neurotrophins, and glycoconjugates. Science 276:1428-1431.

Iwai Y, Usui T, Hirano S, Steward R, Takeichi M, Uemura T (1997) Axon patterning requires $\mathrm{DN}$-cadherin, a novel neuronal adhesion receptor, in the Drosophila embryonic CNS. Neuron 19:77-89.

Kashiwa A, Yoshida H, Lee S, Paladino T, Liu Y, Chen Q, Dargusch R, Schubert D, Kimura H (2000) Isolation and characterization of novel presenilin binding protein. J Neurochem 75:109-116.

Miyatani S, Shimamura K, Hatta M, Nagafuchi Hatta, Nose A, Matsunaga M, Hatta K, Takeichi M (1989) Neural cadherin: role in selective cell-cell adhesion. Science 245:631-635.

Muller T, Choidas A, Reichmann E, Ullrich A (1999) Phosphorylation and free pool of beta-catenin are regulated by tyrosine kinases and tyrosine phosphatases during epithelial cell migration. J Biol Chem 274:10173-10183.

Namekata K, Enokido Y, Iwasawa K, Kimura H (2004) MOCA induces membrane spreading by activating Rac1. J Biol Chem 279:14331-14337.

Piedra J, Martinez D, Castano J, Miravet S, Dunach M, de Herreros AG (2001) Regulation of beta-catenin structure and activity by tyrosine phosphorylation. J Biol Chem 276:20436-20443.

Ramsby ML, Makowski GS (1999) Differential detergent fractionation of eukaryotic cells. Analysis by two-dimensional gel electrophoresis. Methods Mol Biol 112:53-66.

Redies C (2000) Cadherins in the central nervous system. Prog Neurobiol 61:611-648.

Redies C, Takeichi M (1996) Cadherins in the developing central nervous system: an adhesive code for segmental and functional subdivisions. Dev Biol 180:413-423.

Roura S, Miravet S, Piedra J, Garcia de Herreros A, Dunach M 1999 Regulation of E-cadherin/Catenin association by tyrosine phosphorylation. J Biol Chem 274:36734-36740.

Schubert D, Heinemann S, Carlisle W, Tarikas H, Kimes B, Patrick J, Steinbach JH, Culp W, Brandt BL (1974) Clonal cell lines from the rat central nervous system. Nature 249:224-227.

Schubert D, Jin LW, Saitoh T, Cole G (1989) The regulation of amyloid beta protein precursor secretion and its modulatory role in cell adhesion. Neuron 3:689-694.

Sommers CL, Gelmann EP, Kemler R, Cowin P, Byers SW (1994) Alter- ations in beta-catenin phosphorylation and plakoglobin expression in human breast cancer cells. Cancer Res 54:3544-3552.

Steinberg MS, Takeichi M (1994) Experimental specification of cell sorting, tissue spreading, and specific spatial patterning by quantitative differences in cadherin expression. Proc Natl Acad Sci USA 91:206-209.

Stewart DB, Barth AI, Nelson WJ (2000) Differential regulation of endogenous cadherin expression in Madin-Darby canine kidney cells by cell-cell adhesion and activation of beta-catenin signaling. J Biol Chem 275:20707-20716.

Takeichi M (1991) Cadherin cell adhesion receptors as a morphogenetic regulator. Science 251:1451-1455.

Takeichi M (1995) Morphogenetic roles of classic cadherins. Curr Opin Cell Biol 7:619-627.

Tanaka H, Shan W, Phillips GR, Arndt K, Bozdagi O, Shapiro L, Huntley GW, Benson DL, Colman DR (2000) Molecular modification of N-cadherin in response to synaptic activity. Neuron 25:93-107.

Tang L, Hung CP, Schuman EM (1998) A role for the cadherin family of cell adhesion molecules in hippocampal long-term potentiation. Neuron 20:1165-1175.

Taupin P, Ray J, Fischer WH, Suhr ST, Hakansson K, Grubb A, Gage FH (2000) FGF-2-responsive neural stem cell proliferation requires CCg, a novel autocrine/paracrine cofactor. Neuron 28:385-397.

Tomschy A, Fauser C, Landwehr R, Engel J (1996) Homophilic adhesion of E-cadherin occurs by a co-operative two-step interaction of $\mathrm{N}$-terminal domains. EMBO J 15:3507-3514.

Uchida N, Honjo Y, Johnson KR, Wheelock MJ, Takeichi M (1996) The catenin/cadherin adhesion system is localized in synaptic junctions bordering transmitter release zones. J Cell Biol 135:767-779.

Utton MA, Eickholt B, Howell FV, Wallis J, Doherty P (2001) Soluble $\mathrm{N}$-cadherin stimulates fibroblast growth factor receptor dependent neurite outgrowth and $\mathrm{N}$-cadherin and fibroblast growth factor receptor cocluster in cells. J Neurochem 76:1421-1430.

Yagi T, Takeichi M (2000) Cadherin superfamily genes: functions, genomic organization, and neurologic diversity. Genes Dev 14:1169-1180.

Yajnik V, Paulding C, Sordella R, McClatchey AI, Saito M, Wahrer DC, Reynolds P, Bell DW, Lake R, van den Heuvel S, Settleman J, Haber DA (2003) DOCK4, a GTPase activator, is disrupted during tumorigenesis. Cell 112:673-684.

Yap AS, Brieher WM, Gumbiner BM (1997) Molecular and functional analysis of cadherin-based adherens junctions. Annu Rev Cell Dev Biol 13: 119-146. 